\title{
How steroid hormones act on the endothelium-insights by atomic force microscopy
}

\author{
Uta Hillebrand • Martin Hausberg • Detlef Lang • \\ Christian Stock • Christoph Riethmüller • \\ Chiara Callies • Eckhart Büssemaker
}

Received: 4 October 2007 / Accepted: 20 November 2007 / Published online: 3 January 2008

(C) Springer-Verlag 2007

\begin{abstract}
Vascular actions of steroid hormones have gained increasing importance. Indeed, some steroid hormones favorably influence vascular structure and function, whereas others are detrimental. This review will focus on the endothelial effects of steroid hormones. In the first part, we summarize data from in vivo studies elucidating the regulation of endothelial function by steroid hormones. Accumulating data argue for an improvement of endothelium-derived relaxation and impaired vascular contraction by estradiol, whereas testosterone, progesterone, and aldosterone have contrary effects. In the second part, we present data from novel atomic force microscopy studies performed in living endothelial cells under the influence of steroid hormones. These studies provide insight into structural and functional alterations of endothelial cells characterized by changes in volume, apical surface, and stiffness. We summarize the available evidence that changes in shape of endothelial cells translate into changes of endothelial cell stiffness. Under the influence of estradiol, endothelial cells become spherical with consecutive improvement of elasticity, whereas aldosterone flattens endothelial cell-shape leading to increased stiffness. Both, endothelial cell shape and stiffness are major determinants of endothelial nitric oxide production. These studies emphasize the great potential of atomic force microscopy to investigate the function of living endothelial cells.
\end{abstract}

U. Hillebrand $\cdot$ M. Hausberg $(\triangle) \cdot$ D. Lang $\cdot$ E. Büssemaker Medizinische Klinik und Poliklinik D,

Universitätsklinikum Münster,

Albert-Schweitzer-Str. 33,

48149 Münster, Germany

e-mail: hausber@uni-muenster.de

C. Stock $\cdot$ C. Riethmüller $\cdot$ C. Callies

Institut für Physiology II, Westfälische Wilhelms-Universität,

Münster, Germany
Keywords Aldosterone - Glucocorticoids - Sex hormones · Atomic force microscopy $\cdot$ Endothelium · Imaging ·

Nitric oxide

Research over the last two decades has been clearly demonstrating that the vascular endothelium is a target for steroid hormones, e.g., sex hormones, glucocorticoids, and mineralocorticoids $[25,35]$. Indeed, specific receptors for these steroid hormones have been identified in endothelial cells. Numerous clinical studies demonstrate that the various steroid hormones affect vascular function in different ways.

\section{Sex hormones}

Vascular endothelial cells and vascular smooth muscle cells express receptors for estradiol, progesterone, and testosterone $[54,55,66]$. The sex hormones bind to specific cytosolic receptors. The resulting complexes are transported into the nucleus and initiate gene transcription (so-called genomic effects). Moreover, sex hormones cause a number of rapid non-genomic effects on vascular endothelial and smooth muscle cells.

Several studies report gender differences in vascular function. Vascular contraction was found to be greater in male and ovarectomized female rats than in castrated male and female rats, suggesting an effect of testosterone in favor of vascular contraction and an effect of estradiol in favor of preventing vascular contraction [24]. Specifically, estradiol has been shown to cause endothelium-mediated vasorelaxation, whereas testosterone and progesterone interfere with estradiol-mediated endothelium-dependent vasodilation [25].

There is a body of evidence suggesting that sex hormones interfere with the synthesis and bioavailability of endothelium- 
derived nitric oxide (NO) $[10,58]$. Animal studies show that the release of NO from the endothelium is greater in female than in male rats $[19,62]$. Indeed, estradiol induces endothelial nitric oxide synthase (eNOS) expression, mediated via the estradiol receptor alpha. Moreover, estradiol interacts with estradiol receptors in the cell membrane and causes rapid non-genomic signaling pathways that regulate eNOS activity, partly by eNOS translocation to the cell membrane. In addition to stimulating NO synthesis, estradiol has antioxidant effects and inhibits superoxide formation and, thereby, increases NO bioavailability [41]. On the other hand, progesterone and testosterone may have some stimulatory effect on NO production, but progesterone has been shown to counteract the stimulatory effects on NO release $[41,66]$.

Sex hormones differentially affect cyclooxygenase expression in endothelial cells, where particularly estradiol causes an increase in cyclooxygenase type 1 expression an prostaglandin $\mathrm{I}_{2}$ production [41].

Moreover, sex hormones interact with endotheliumderived contracting factors. Estradiol attenuates endothelin 1 (ET-1) and endothelin beta receptor messenger RNA (mRNA) expression and inhibits ET-1 production in endothelial cells. Furthermore, progesterone inhibits endothelial ET-1 production, whereas testosterone stimulates ET-1 release from the endothelium [11, 66].

\section{Glucocorticoids}

There is substantial evidence that glucocorticoids downregulate eNOS mRNA and protein expression in cultured endothelial cells and also in the isolated vessels [59]. Moreover, glucocorticoids suppress the production of endothelium-derived vasodilators. Glucocorticoid excess causes increased superoxide formation, thus increased oxidative stress in endothelial cells [22]. However, a recent study did not show any change of endothelium-mediated vasodilatation with short-term dexamethasone application in healthy subjects [7]. On the other hand, in states of inflammation, glucocorticoid treatment may improve endothelial function. For example, in patients with giant cell arteritis, steroid treatment was associated with an improvement of brachial artery flow-mediated dilatation [15]. Interestingly, shear stress caused a nuclear localization of the endothelial glucocorticoid receptor similar to that induced by high-dose steroid treatment, suggesting an antiatherosclerotic effect of glucocorticoids [23]. Additionally, glucocorticoids reduce endothelial permeability and interfere with the production and action of adhesion molecules. For example, dexamethasone was shown to reduce cytokine-induced expression of intercellular adhesion molecule 1 (ICAM-1) and vascular cell adhesion molecule 1 in cultured endothelial cells. By contrast, sex hormones had no substantial effect on endothelial adhesion molecule expression [9].

It has to be noted though that glucocorticoid action in endothelial cells depends on the activity of 11-betahydroxysteroid dehydrogenase. Abnormal 11-beta-hydroxysteroid dehydrogenase expression or function will cause mineralocorticoidrecpetor activation by glucocorticoids. This will ensue mineralocorticoid-like action of glucocorticoids on the vascular endothelium [67].

\section{Aldosterone}

Several clinical studies show that aldosterone impairs vascular reactivity $[4,8,27,46]$. Interestingly, the mechanisms are not completely understood. Aldosterone increases reactive oxygen species in endothelial cells and reduces the bioavailability of NO [29]. This is associated with impaired endothelium-mediated vasodilatation [56], that can be reversed with aldosterone antagonists as has been shown in disease states such as heart failure [1]. Reduced NO bioavailability with aldosterone appears to be attributable to decreased eNOS activity. This may result from decreased levels of tetrahydrobiopterine, as normal levels depend on adequate nicotinamide adenine dinucleotide phosphate, reduced form (NADPH) levels [29].

A recent study shows that aldosterone decreases glucose-6phosphate dehydrogenase activity [29]. Decreased glucose6-phosphate dehydrogenase activity results in decreased NADPH levels and thus increases oxidative stress-with the consequences of reduced eNOS activity in increased levels of reactive oxygen species. The authors, moreover, have shown that aldosterone antagonists restore glucose6-phosphate dehydrogenase activity and thereby improve vascular reactivity in vivo. Aldosterone effects could be mimicked by experimental deficiency of glucose-6-phosphate dehydrogenase.

Aldosterone treatment also adversely affects adhesion molecules. Increased deposition of ICAM-1 has been demonstrated in the vascular wall of aldosterone-infused rats [45]. Spironolactone and endothelin antagonist treatment reduced ICAM-1 content and reversed NAPDH depletion in the vascular wall. Aldosterone directly induces endothelin expression in vivo [63].

Importantly, aldosterone effects on endothelial function, oxidative stress, and adhesion molecules, and endotheliumderived contracting factors are associated with vascular fibrosis and profound vascular stiffening [27]. Large artery stiffness is related to aldosterone concentrations in hypertensive subjects [4]. Aldosterone causes cardiac fibrosis as shown in patients with heart failure [57]. Moreover, increased aldosterone levels induce renal vascular and tubulointerstitial fibrosis in several patient collectives such 
as diabetics and patients with heart failure or renal disease [56].

What does atomic force microscopy add to our understanding of the in vivo functional effects of steroid hormones on the endothelium?

Atomic force microscopy (AFM) allows structural [3] and, importantly, also functional imaging of endothelial cells. There is a solid body of evidence that endothelial cell structure influences endothelial cell function. These experimental data are - to a large extent-derived from AFM studies [32, 37, 38, 51].

The micromechanical structure of the endothelial cell membrane is characterized by a polygonal mesh of mostly actin and vimentin fibers [43]. This complex structure is in a process of constant remodeling [44]. Mechanical stimuli that act on the endothelial cell determine this process of endothelial cell cortex remodeling [12]. It is intriguing that endothelial cell shape and NO have profound influences on the cytoskeleton. In a recent study, shape-engineered endothelial cells were characterized [26]. Spindle-shaped cells displayed reduced NO production and increased stiffness that were related to dense actin stress fibers. By contrast, large circular-shaped endothelial cells, which displayed increased NO production, were soft and lacked dense actin stress fibers. It is conceivable that NO bioavailability determines endothelial cell cytoskeleton and elastic properties, as NO may depolymerize actin [20]. On the other hand, increased endothelial cell elasticity may be associated with translocation of eNOS to the cell membrane and hence increase eNOS activity [28]. There is further evidence that endothelial cell elastic properties and NO production are related to each other. Peng et al. [42] studied NO production in endothelial cells that were grown in tubes and subjected to pulsatile flow. When the elastic response of the endothelial cells to pulsatile flow was restricted by using a rigid tube, endothelial cell NO production was reduced markedly. This was associated with increased endothelial cell vulnerability to ultraviolet radiation.

From these observations, it appears that endothelial cell elastic properties are closely related to endothelial NO production and that, again, endothelial morphological properties at least in part determine endothelial cell elasticity. Thus, endothelial cell stiffness appears as a marker of endothelial cell function.

These important parameters - endothelial cell morphological properties and elastic properties - can only be assessed in living endothelial cells by AFM. We have performed AFM studies regarding the effects of the various steroid hormones outlined above on endothelial cell properties. We observed divergent effects - in line with the divergent effects of steroid hormones on clinically relevant parameters $[17,18,37]$.

Which parameters can be assessed by atomic force microscopy in endothelial cells?

AFM is a nanotechnique that allows exact imaging of the surface of living cells $[33,52]$. Importantly, AFM is a scanning procedure that relies on a mechanical sensor with defined properties. A tiny tip is mounted on a cantilever holder. This tip follows the surface contour of the sample and yields an exact image of the surface topography at a very high resolution up to several nanometers. Importantly, detailed topographical surface scans are obtained, allowing the quantification of the roughness of any rippled surface. Moreover, AFM is an excellent tool to quantify the volume of cells adherent to a nondeformable surface under in vivo conditions and independent of the morphology of the cells [50]. Many AFM studies were performed on endothelial cells fixed with glutaraldehyde, as image quality generally is higher with fixed cells $[18,17]$. As living endothelial cells are more deformable than fixed endothelial cells, AFM measurements performed in living endothelial cells tend to underestimate cell volume and surface; however, these differences between fixed and living cells are only slight and generally negligible [37]. The exact morphology of cellcell contacts can be visualized. In addition, the technique is also applicable to cell substructures allowing nanoscale imaging of cell membranes, the cell nucleus, membrane protein clusters such as nuclear pores [34, 39, 47, 49, 53].

AFM can be performed under physiological conditions, i.e., at $37^{\circ} \mathrm{C}$ in fluid. For this purpose, cells are covered by some amount of culture medium. Therefore, it is possible to scan living cells. AFM is particularly able to scan endothelial cells under in vivo conditions. As the mechan-

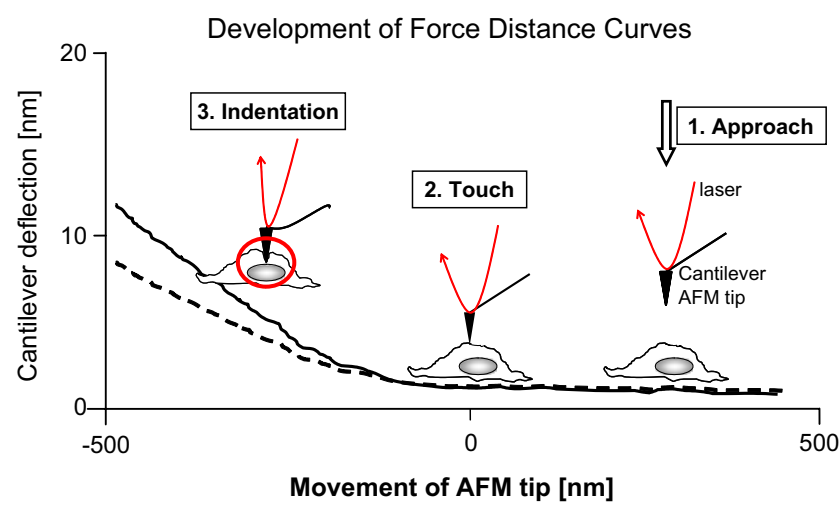

Fig. 1 Sketch of the development of force distance curves: 1. The AFM tip approaches the cell surface. 2. The AFM tip touches the cell surface. 3. Further movement of the AFM tip leads to an indentation of the cell surface. The indentation of the cell surface causes a deflection of the laser beam which correlates to the force needed to indent the cell surface. The stronger the deflection, the stiffer the surface is 
ical properties of the cantilever are defined, it is feasible to measure the stiffness of the surface scanned. When the AFM tip is pressed against the surface, the deflection of the cantilever is measured. From these measurements, the force necessary to indent a cell for a certain distance can be calculated. These forces relate directly to cell stiffness [33]. A schematic view of the development of force-distance curves is delineated in Fig. 1.

In summary, AFM is the only experimental approach to assess both microstructure and elasticity of living cells. These parameters of endothelial cells are-as outlined above - closely related to endothelial function.
What are the effects of steroid hormones on endothelial cells as assessed by atomic force microscopy?

We have studied the effects in various types of vascular endothelial cells including human umbilical vein endothelial cells (HUVEC), the endothelial cell line EAHy926, bovine aortic endothelial cells (GM7373), and human coronary artery endothelial cells.

The effects of sex hormones and glucocorticoids were studied in HUVEC exposed for $72 \mathrm{~h}[17,37]$. A major effect was observed with estradiol. Estradiol at physiological concentrations (up to $15 \mathrm{nmol} / \mathrm{l}$ ) produced substantial dose- a

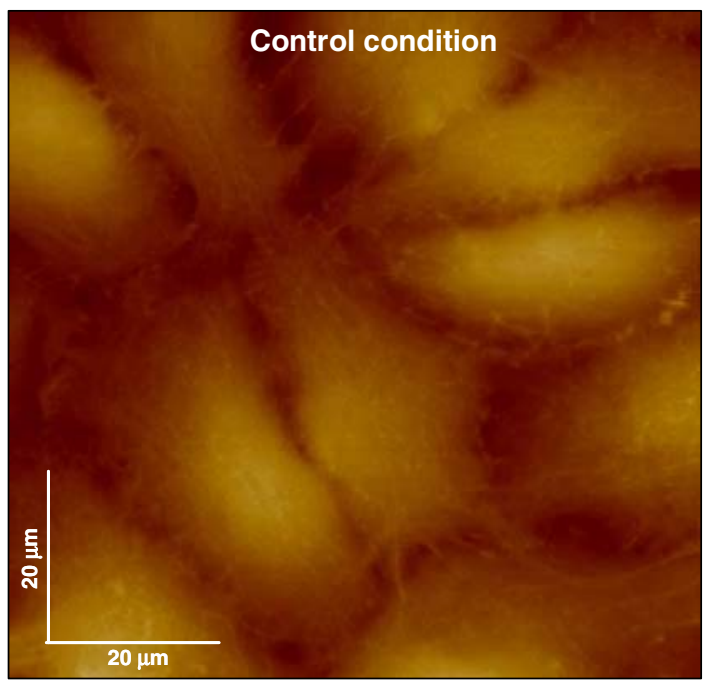

C

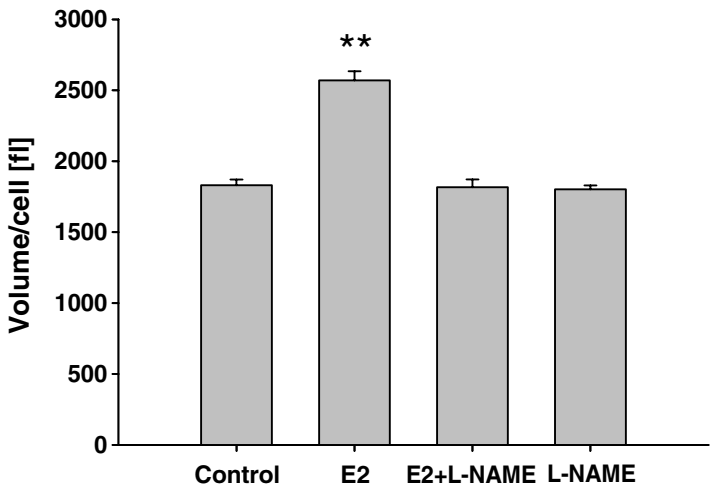

Fig. 2 Top view AFM images of fixed HUVEC under (a) control conditions and (b) after 72 hours treatment with $15 \mathrm{nmol} / 1$ estradiol (E2). The scanned area in both pictures is $80 \mu \mathrm{m} \times 80 \mu \mathrm{m}$, the height of the cells is depicted by the coloured bar, allowing a three dimensional reconstruction of the cells ( 0 to $8 \mu \mathrm{m}$ ). It is evident, that HUVEC under estradiol treatment have increased height and size compared to controls. In (c) volume per cell is shown after 72 hours of treatment with estradiol $(15 \mathrm{nmol} / \mathrm{l})$, the inhibitor of the nitric oxide synthase L NAME $(1 \mathrm{mmol} / \mathrm{l})$ b

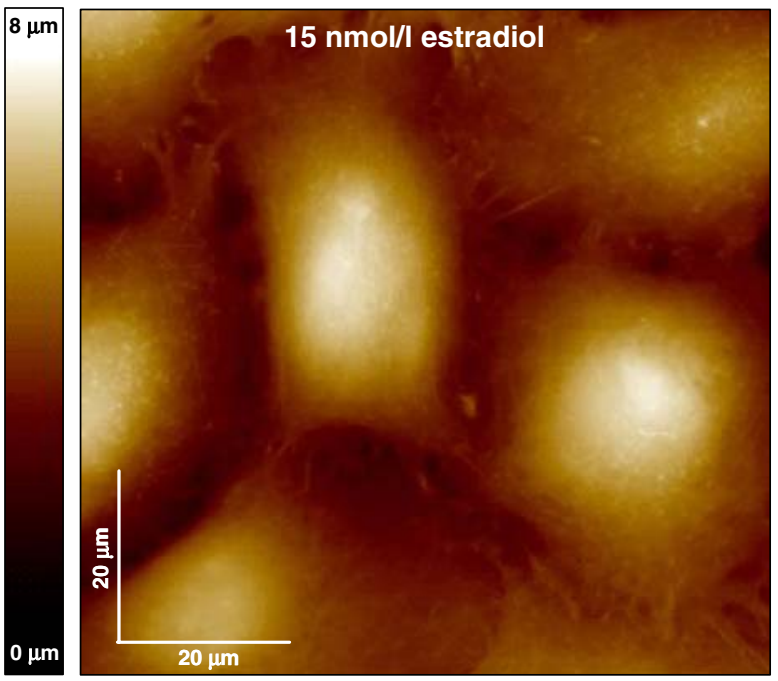

d

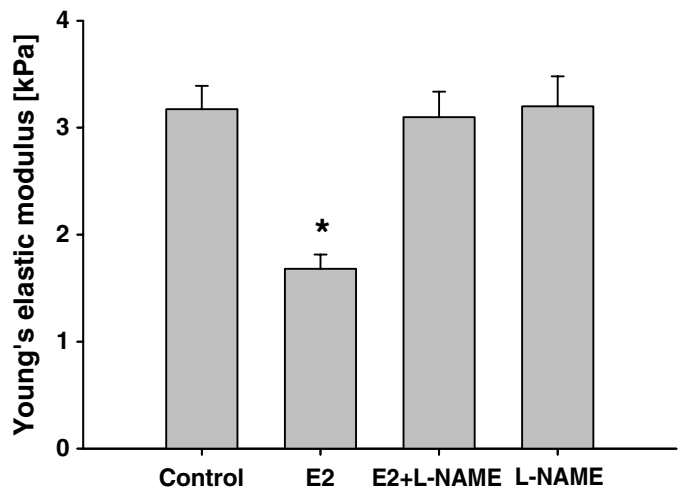

or combination of E2 and L NAME compared to controls. Cell volume increased significantly with estradiol treatment. This effect can be inhibited by simultaneous incubation with L NAME, indicating that the estradiol induced changes are nitric oxide dependent $(n=20, * * p<0.01)$. (d) Effect of E2 with and without L NAME on stiffness (shown as Young's elastic modulus in $\mathrm{kPa}$ ) in living HUVEC compared to control conditions (control, L NAME, $\mathrm{n}=15, * \mathrm{p}<0.05$ ). Modified after Hillebrand et al. [18] 
dependent endothelial cell growth with an increase in cell volume by up to approximately $40 \%$. Apical surface area also increased, but only by about $20 \%$. These morphological changes are consistent with spherical transformation of endothelial cells along with a smoothing of the surface. These morphological changes were associated with a substantial decrease of cell stiffness. The force necessary to indent the endothelial cell membrane by $300 \mathrm{~nm}$ was roughly halved with estradiol treatment. All estradiol effects could be abolished by coincubation with tamoxifen. Although tamoxifen is not a highly specific estradiol receptor antagonist, this suggests that the observed estradiol effects were dependent on estradiol receptors present in endothelial cells (Fig. 2).

By contrast, neither progesterone nor testosterone nor dexamethasone significantly influenced endothelial cell shape, volume, surface area, or stiffness.

The estradiol effects on endothelial cell growth were mainly attributable to intracellular water and electrolyte accumulation and only to some degree to an increase in organic cell matter. We could show that the increase in cell water with estradiol was caused by activation of the sodium proton exchanger NHE1 and could be prevented by the specific NHE1 inhibitor cariporide (HOE642). It is known that steroid hormones can alter the set-point of the sodium proton exchanger with the results of a more alkaline intracellular milieu and cell volume expansion [40].

These AFM studies show related structural and functional changes in endothelial cells with estradiol. With estradiol, cells become spherical and smooth their cell membrane surface. These morphological changes go along with decreased cell stiffness. The decreased cell stiffness with estradiol could have a simple biomechanical explanation. According to the law of Laplace $[F=\delta 2 \times$ $(2 / \Pi) \times[E /(1-v 2)] \times \tan (\alpha) ; F=$ applied force (calculated from the spring constant $[0.01 \mathrm{~N} / \mathrm{m}]$ multiplied by the measured cantilever deflection), $E=$ elastic modulus $(\mathrm{kPa})$, $\nu=$ Poisson's ratio assumed to be 0.5 because the cell was considered incompressible, $\alpha=$ opening angle of the AFM tip $\left(35^{\circ}\right)$, and $\delta=$ indentation depth], sphere segments with a small radius (a model for an endothelial cell under the influence of estradiol) are less stiff than sphere segments with a larger radius, as the stiffness of a spherical body correlates with the radius of the sphere. However, it is likely that more complex mechanisms underlie the observed structural and functional effects of estradiol. As outlined above, experiments in shape-engineered endothelial cells show that round-shaped cells lack actin stress fibers, are more elastic, and exhibit increased NO production [26]. Thus, reduced stiffness means increased NO production, i.e., improved endothelial function. Indeed, recent studies suggest that functional endothelial cell changes by estradiol receptor activation are associated with translocation of the eNOS and altered expression of the endogenous eNOS inhibitor caveolin [28]. A spherical endothelial cell adapts more easily to changes in vessel wall diameter, i.e., stretches more easily with dilatation of the vessel or increased shear stress. The response to shear stress can be transmitted more easily in spherical endothelial cells. This could result in more pronounced eNOS activation [26]. We could further substantiate these data by our own findings showing that the estradiol-induced increase in cell volume and surface as well as the pronounced decrease in endothelial stiffness is NO dependent [17].

The observed effects visualized by AFM-substantial cell growth and reduced stiffness only with estradiol, not with progesterone, testosterone, or glucocorticosteroidsare consistent with the effects on endothelial function outlined above. Whereas studies on the endothelial effects of estradiol unequivocally showed improved endothelial function and increased eNOS activity, studies on the action of progesterone, testosterone, or glucocorticoids on the vascular endothelium showed inconsistent or only small effects $[7,9,15,22,25,41]$.

There is a solid body of evidence derived from AFM studies regarding the effects of mineralocorticoids on the

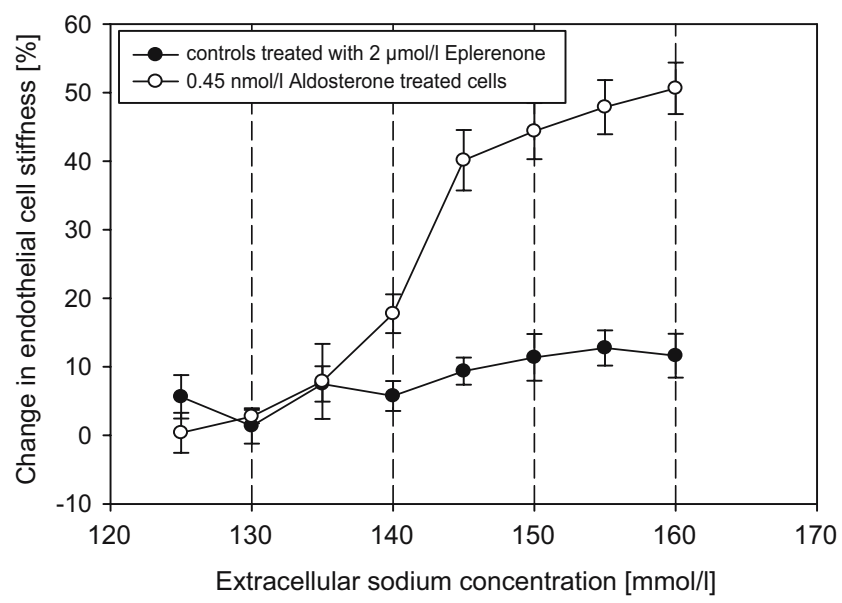

Fig. 3 Changes in endothelial cell stiffness in EAHy926 cells under control conditions (black dot line) versus aldosterone treatment (white dot line) in response to increasing sodium concentrations in the buffered electrolyte solution are revealed. Controls were treated with $2 \mu \mathrm{mol} / 1$ eplerenone for inhibition of possible endogenous aldosterone secretion by the endothelial cells. Aldosterone was used in physiological concentrations of $0.45 \mathrm{nmol} / 1$. Sodium concentrations were varied between 125 and $160 \mathrm{mmol} / \mathrm{l}$ and osmolality was kept constant by adequate addition of mannitol. Force curves were obtained by scanning the same selected endothelial cells under varying sodium concentrations every 3 minutes. Stiffness measurements at $125 \mathrm{mmol} / 1$ sodium in the solution (reference solution) served as the reference value. Deviation from reference values (in \%) are reported here. Mean values of 10 independent measurements per series of experiments are given as +/- SEM. In aldosterone treated endothelium, mean values for stiffness at sodium concentrations above $140 \mathrm{mmol} / 1$ are significantly higher compared to mean values measured at $125 \mathrm{mmol} / \mathrm{l}$ sodium $(\mathrm{p}<0.01)$. However, stiffness does not increase with rising sodium concentrations in eplerenone treated controls $(p<0.01)$. Modified after Oberleithner et al. [38] 
Fig. 4 Top view AFM images of HUVEC monolayers grown for 3 days in presence of $1 \mathrm{nM}$ aldosterone and then perfused with blood. Please note the large gaps between cells (indicated by stars). Gaps indicate lack of cells. Images sizes: $\mathrm{A}=70 \mathrm{x}$ $70 \mu \mathrm{m}^{2}, \mathrm{~B}=100 \times 100 \mu \mathrm{m}^{2}$; $\mathrm{C}$ and $\mathrm{D}=50 \times 50 \mu^{2}$. Taken from Oberleithner et al. [36]
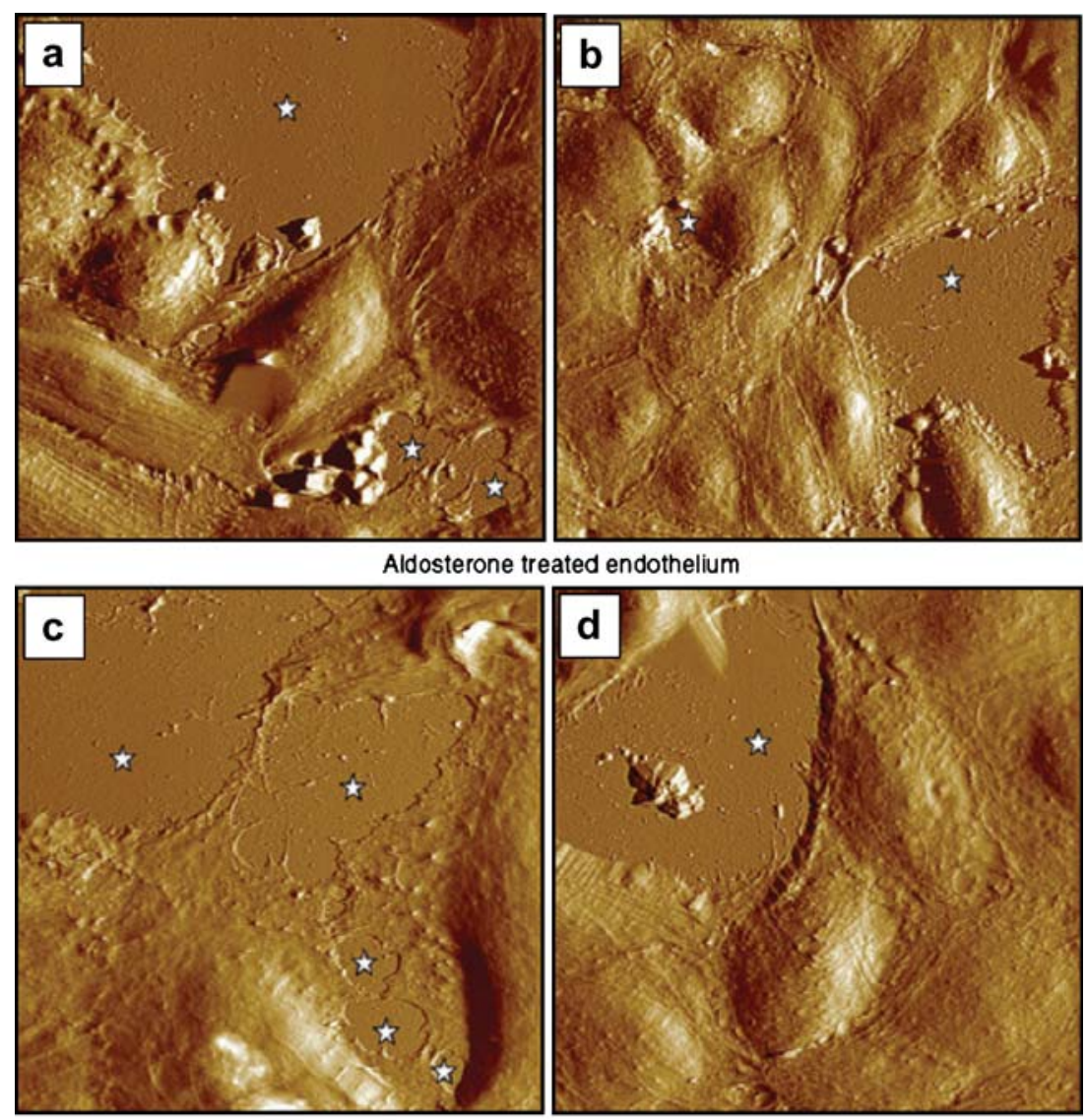

vascular endothelium $[6,31,38]$. From these studies, it appears that the effects of aldosterone are opposite to the effects of estradiol. We were able to show that aldosterone dose-dependently increases endothelial cell volume and apical surface [18]. The effects were consistent in HUVEC, EAHy926, human coronary artery endothelial cells, and bovine aortic endothelial cells, i.e., in cells of both venous and arterial origin $[18,33]$. Importantly, opposite to the estradiol effects, with aldosterone cell surface, increased to a much larger extent than volume. Surface was augmented by more than $60 \%$, whereas volume increased only by less than $20 \%[33,35]$. The morphological correlate was a flattening of the cells along with some rippling of the cell membrane [33]. This means that endothelial cells contract

Table 1 Morphological and functional changes of endothelial cells imaged by atomic force microscopy after treatment with estradiol, progesterone, testosterone, aldosterone and prednisolone

\begin{tabular}{|c|c|c|c|c|c|}
\hline & Estradiol & Progesterone & Testosterone & Aldosterone & Prednisolone \\
\hline Volume & ++ & 0 & 0 & + & 0 \\
\hline $\begin{array}{l}\text { Apical } \\
\text { surface }\end{array}$ & + & 0 & 0 & +++ & 0 \\
\hline Shape & $\begin{array}{l}\text { Spherical transformation, } \\
\text { smoothing of cell surface }\end{array}$ & 0 & 0 & $\begin{array}{l}\text { Flattening of the cells, rippling } \\
\text { of cell surface }\end{array}$ & 0 \\
\hline Stiffness & - & 0 & 0 & +++ & 0 \\
\hline Mechanism & $\begin{array}{l}\text { Activation of estradiol receptor, } \\
\text { NHE1, eNOS }\end{array}$ & & & $\begin{array}{l}\text { Activation of mineralocorticoid } \\
\text { receptor, } \mathrm{ENaC}\end{array}$ & \\
\hline Interpretation & $\begin{array}{l}\text { Beneficial effect: increased } \\
\text { elasticity by round-shaped } \\
\text { endothelial cells; increased } \\
\text { production of NO }\end{array}$ & $\begin{array}{l}\text { No effect on } \\
\text { shape and } \\
\text { stiffness }\end{array}$ & $\begin{array}{l}\text { No effect on } \\
\text { shape and } \\
\text { stiffness }\end{array}$ & $\begin{array}{l}\text { Detrimental effect: contraction of } \\
\text { cells; disruption of cell layer under } \\
\text { shear stress; increased vulnerability; } \\
\text { reduced NO production }\end{array}$ & $\begin{array}{l}\text { No effect on } \\
\text { shape and } \\
\text { stiffness }\end{array}$ \\
\hline
\end{tabular}

0 : no change; +/-: slight increase/decrease; ++/-: moderate increase/decrease; +++/-: strong increase/decrease

Data are presented as compared to control experiments. 
under the influence of aldosterone (Fig. 4). Substantial effects already occurred with low doses of aldosterone, corresponding to mild hyperaldosteronism [18].

The aldosterone-induced alterations of endothelial cell morphology that were opposite to the estradiol effects also were associated with opposite effects on endothelial cell biomechanical properties. Using AFM as a mechanosensor, we observed that, with aldosterone, endothelial stiffness increased dose dependently. Again, substantial effects were already observed with relatively low aldosterone levels corresponding to mild elevations of plasma aldosterone such as observed in hypertension or mild to moderate heart failure [18].

Thus, endothelial cell contraction was associated with endothelial cell stiffening. This finding is consistent with the aforementioned studies in shape-engineered endothelial cells. Spindle-shaped endothelial cells displayed dense actin filaments and reduced NO production [26]. We were able to relate endothelial cell stiffening with aldosterone to reduced NO production [38]. Aldosterone-treated bovine aortic endothelial cells that were exposed to shear stress displayed reduced nitrite concentrations in the culture medium, thus reduced NO formation, along with stiffening of these cells. It is important that aldosterone effects on the vascular endothelium depend on sodium concentrations. After $72 \mathrm{~h}$ of aldosterone incubation in physiological concentration $(0.45$ $\mathrm{nmol} / \mathrm{l}$ ), endothelial cell stiffness was unaffected by acute changes in sodium concentration below $135 \mathrm{mmol} / \mathrm{l}$ but rose steeply between 135 and $145 \mathrm{mmol} / \mathrm{l}$. The increase in stiffness occurred within minutes (Fig. 3). These data show that plasma sodium per se-within a small physiological concentration range - alters vascular endothelial cell stiffness and NO production, but this occurs only under a permissive influence of aldosterone. The effects were independent of osmolality that was kept constant by variable addition of mannitol [38].

Aldosterone-induced morphological alteration and stiffening of endothelial cells depend on activation of the mineralocorticoid receptor [14]. However, both fast non-genomic and genomic effects are involved [13]. Aldosterone effects can be completely abolished by mineralocorticoid receptor antagonists such as spironolactone and eplerenone.

Importantly, aldosterone-induced changes in the vascular endothelium depend on activation of the epithelial sodium channel [35]. This is in contrast to estradiol where cell swelling depends on the sodium proton exchanger and is independent of the $\mathrm{ENaC}$. Incubation with the $\mathrm{ENaC}$ blocker amiloride prevented the endothelial effects of aldosterone. In a recent study, the time course of aldosterone action on endothelial cells was analyzed [33]. During the first minutes after addition of aldosterone, there was a transient increase in cell volume along with a decrease in cell stiffness. However, after $15 \mathrm{~min}$, cell volume decreased again, and cell stiffness increased progressively. This was associated with endothelial cell contraction. Similar effects were observed in renal epithelial cells [16]. A recent observation suggests that intracellular sodium regulates the open probability of the $\mathrm{ENaC}$ [2]. Thus, the initial
Fig. 5 AFM images taken before (control; time $=0$ ) and after acute exposure of human endothelial cells to $1 \mathrm{nM}$ aldosterone. a) Visible is a portion of a living endothelial cell maintained in a buffered solution at $37^{\circ} \mathrm{C}$. The cell apears relaxed. b) Same cell as in a), 23 minutes after aldosterone exposure. The cell appears contracted.

c) Visible is a $25 \mu \mathrm{m} 2$ plasma membrane patch. The membrane appears smooth. d) Same membrane patch as in c) but after aldosterone exposure. Surface roughness is found strongly increased. Taken from Oberleithner et al. [33]
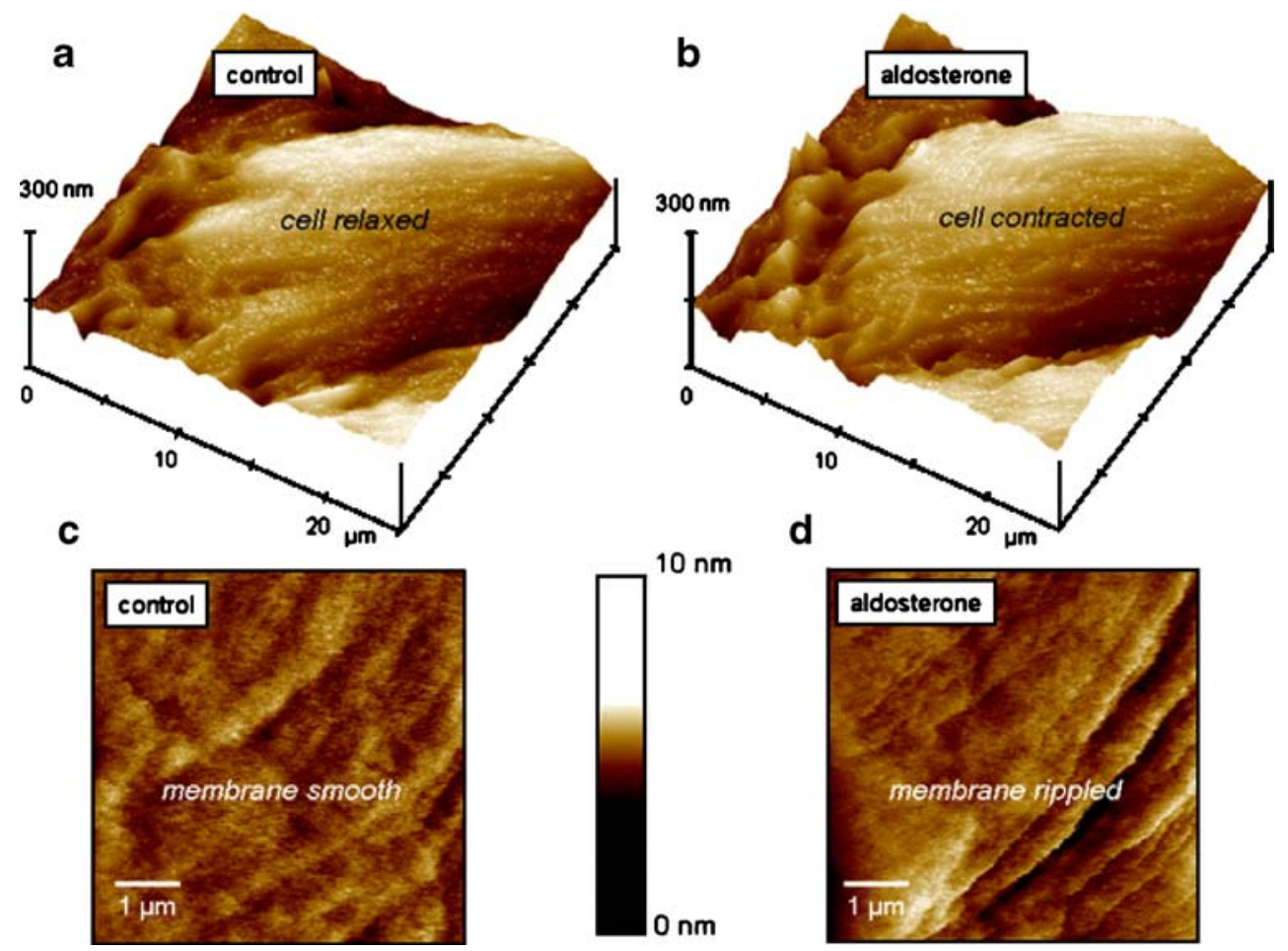
increase in intracellular sodium during aldosterone incubation could limit further sodium entry into the endothelial cell and initiate volume regulation and the observed cell contraction during continued aldosterone exposure. After further exposition to aldosterone during several days, endothelial cell volume increases again. However, this is to a significant degree due to accumulation of organic material [36]. Endothelial cell stiffening is a consistent finding also after prolonged aldosterone exposure [18].

Table 1 summarizes the morphological and functional changes of endothelial cells imaged by AFM after treatment with steroid hormones.

Is endothelial cell stiffening with aldosterone detrimental as opposed to endothelial cell "softening" with estradiol?

As outlined above, an increase in endothelial cell stiffness measured by AFM is associated with reduced NO production. This finding is consistent in studies by different groups. However, beyond reduced NO production and reduced eNOS activity, endothelial cell stiffening has additional functional implications. Peng et al. [42] showed that, when the elastic deformation in response to pulsatile stress was hindered, endothelial cells became vulnerable to ultraviolet radiation. Oberleithner et al. [36] studied the responses of endothelial cell monolayers to prolonged shear stress in the presence of aldosterone. Along with endothelial cell stiffening, there was a disruption of the endothelial cell layer with aldosterone treatment [36, 37]. The aldosterone-induced endothelial cell contraction and stiffening first led to paracellular gap formation. With continued shear stress, endothelial cells could not withstand the strain and were disrupted from the layer (Fig. 4) [36]. Thus, aldosterone-induced contraction and stiffening of the vascular endothelium make it vulnerable to mechanical stress. Indeed, endothelial lesions with denudation of the basal membrane represent a common phenomenon observed in the process of human atherosclerosis [30]. Figure 5.

Endothelial cell stiffening may even be related to the elastic properties of the vascular bed. It has been clearly shown that aldosterone stiffens large arteries [4]. Increased endothelial cell stiffness with aldosterone as opposed to reduced cell stiffness by estradiol may even contribute to vascular deformability, at least in small vessels lacking a marked vascular smooth muscle layer [21]. Under pathophysiological conditions with increased pulse pressure and an altered myogenic tone of small arteries and arterioles, pulsatile stress is transmitted to microvessels, which results in microvascular damage and altered pulse wave reflection [48]. In this context, it is tempting to speculate that altered endothelial cell stiffness may alter pulse wave reflection and thereby contribute to systemic arterial stiffness.
Finally, there is substantial evidence that adhesion of leukocytes or platelets to endothelial cells is associated with reduced NO bioavailability $[5,65]$ and endothelial cell stiffening [60], such as observed with aldosterone [61, 64]. In contrast, the estradiol-induced increase in endothelial elasticity might be associated with reduced leukocyte adhesion and impaired transmigration through the endothelium.

In summary, the outlined AFM studies regarding steroid hormone effects on the vascular endothelium clearly show that AFM allows functional imaging of living endothelial cells. These AFM studies show consistent changes of morphology and stiffness in endothelial cells. Endothelial cell stiffness, as measured by AFM, emerges as an important parameter of endothelial cell function that is not only related to NO bioavailability but to several other endothelial cell functional properties.

Acknowledgments The study was supported by a grant from the Else-Kroener Fresenius Foundation, by an EU grant Tips4Cells and by a grant from the Faculty of Medicine, University of Muenster, IMF HI 120615 . The technical support of Digital Instruments (VEECO, Mannheim) is gratefully acknowledged.

\section{References}

1. Abiose AK, Mansoor GA, Barry M, Soucier R, Nair CK, Hager D (2004) Effect of spironolactone on endothelial function in patients with congestive heart failure on conventional medical therapy. Am J Cardiol 93:1564-1566

2. Anantharam A, Tian Y, Palmer LG (2006) Open probability of the epithelial sodium channel is regulated by intracellular sodium. J Physiol 574:333-347

3. Binnig G, Quate CF, Gerber C (1986) Atomic force microscope. Phys Rev Lett 56:930-934

4. Blacher J, Amah G, Girerd X, Kheder A, Ben Mais H, London GM, Safar ME (1997) Association between increased plasma levels of aldosterone and decreased systemic arterial compliance in subjects with essential hypertension. Am J Hypertens 10:1326-1334

5. Bouzin C, Brouet A, De Vriese J, Dewever J, Feron O (2007) Effects of vascular endothelial growth factor on the lymphocyte-endothelium interactions: identification of caveolin-1 and nitric oxide as control points of endothelial cell anergy. J Immunol 178:1505-1511

6. Brandes RP (2007) Avoiding vicious circles: mineralocorticoid receptor antagonism prevents vascular oxidative stress early after myocardial infarction. Hypertension 50:842-843

7. Brotman DJ, Girod JP, Garcia MJ, Patel JV, Gupta M, Posch A, Saunders S, Lip GY, Worley S, Reddy S (2005) Effects of shortterm glucocorticoids on cardiovascular biomarkers. J Clin Endocrinol Metab 90:3202-3208

8. Brown NJ (2005) Aldosterone and end-organ damage. Curr Opin Nephrol Hypertens 14:235-241

9. Chen W, Lee JY, Hsieh WC (2002) Effects of dexamethasone and sex hormones on cytokine-induced cellular adhesion molecule expression in human endothelial cells. Eur J Dermatol 12:445-448

10. Collins P, Shay J, Jiang C, Moss J (1994) Nitric oxide accounts for dose-dependent estrogen-mediated coronary relaxation after acute estrogen withdrawal. Circulation 90:1964-1968

11. David FL, Carvalho MH, Cobra AL, Nigro D, Fortes ZB, Reboucas NA, Tostes RC (2001) Ovarian hormones modulate 
endothelin-1 vascular reactivity and mRNA expression in DOCAsalt hypertensive rats. Hypertension 38:692-696

12. Davies PF, Zilberberg J, Helmke BP (2003) Spatial microstimuli in endothelial mechanosignaling. Circ Res 92:359-370

13. Funder JW (2005) The nongenomic actions of aldosterone. Endocr Rev 26:313-321

14. Golestaneh N, Klein C, Valamanesh F, Suarez G, Agarwal MK, Mirshahi M (2001) Mineralocorticoid receptor-mediated signaling regulates the ion gated sodium channel in vascular endothelial cells and requires an intact cytoskeleton. Biochem Biophys Res Commun 280:1300-1306

15. Gonzalez-Juanatey C, Llorca J, Garcia-Porrua C, SanchezAndrade A, Martin J, Gonzalez-Gay MA (2006) Steroid therapy improves endothelial function in patients with biopsy-proven giant cell arteritis. J Rheumatol 33:74-78

16. Gorelik J, Zhang Y, Sanchez D, Shevchuk A, Frolenkov G, Lab M, Klenerman D, Edwards C, Korchev Y (2005) Aldosterone acts via an ATP autocrine/paracrine system: the Edelman ATP hypothesis revisited. Proc Natl Acad Sci USA 102:15000-15005

17. Hillebrand U, Hausberg M, Stock C, Shahin V, Nikova D, Riethmuller C, Kliche K, Ludwig T, Schillers H, Schneider SW, Oberleithner H (2006) 17beta-estradiol increases volume, apical surface and elasticity of human endothelium mediated by $\mathrm{Na}+/ \mathrm{H}+$ exchange. Cardiovasc Res 69:916-924

18. Hillebrand U, Schillers H, Riethmuller C, Stock C, Wilhelmi M, Oberleithner H, Hausberg M (2007) Dose-dependent endothelial cell growth and stiffening by aldosterone: endothelial protection by eplerenone. J Hypertens 25:639-647

19. Huang A, Sun D, Koller A, Kaley G (1997) Gender difference in myogenic tone of rat arterioles is due to estrogen-induced, enhanced release of NO. Am J Physiol 272:H1804-H1809

20. Hutcheson IR, Griffith TM (1996) Mechanotransduction through the endothelial cytoskeleton: mediation of flow- but not agonistinduced EDRF release. Br J Pharmacol 118:720-726

21. Ibegbuna V, Nicolaides AN, Sowade O, Leon M, Geroulakos G (1997) Venous elasticity after treatment with Daflon $500 \mathrm{mg}$. Angiology 48:45-49

22. Iuchi T, Akaike M, Mitsui T, Ohshima Y, Shintani Y, Azuma H, Matsumoto T (2003) Glucocorticoid excess induces superoxide production in vascular endothelial cells and elicits vascular endothelial dysfunction. Circ Res 92:81-87

23. Ji JY, Jing H, Diamond SL (2003) Shear stress causes nuclear localization of endothelial glucocorticoid receptor and expression from the GRE promoter. Circ Res 92:279-285

24. Kanashiro CA, Khalil RA (2001) Gender-related distinctions in protein kinase $\mathrm{C}$ activity in rat vascular smooth muscle. Am J Physiol Cell Physiol 280:C34-C45

25. Khalil RA (2005) Sex hormones as potential modulators of vascular function in hypertension. Hypertension 46:249-254

26. Kidoaki S, Matsuda T (2007) Shape-engineered vascular endothelial cells: nitric oxide production, cell elasticity, and actin cytoskeletal features. J Biomed Mater Res A 81:728-735

27. Lacolley P, Labat C, Pujol A, Delcayre C, Benetos A, Safar M (2002) Increased carotid wall elastic modulus and fibronectin in aldosterone-salt-treated rats: effects of eplerenone. Circulation 106:2848-2853

28. Ladage D, Brixius K, Hoyer H, Steingen C, Wesseling A, Malan D, Bloch W, Schwinger RH (2006) Mechanisms underlying nebivololinduced endothelial nitric oxide synthase activation in human umbilical vein endothelial cells. Clin Exp Pharmacol Physiol 33:720-724

29. Leopold JA, Dam A, Maron BA, Scribner AW, Liao R, Handy DE, Stanton RC, Pitt B, Loscalzo J (2007) Aldosterone impairs vascular reactivity by decreasing glucose-6-phosphate dehydrogenase activity. Nat Med 13:189-197
30. Mayranpaa MI, Resendiz JC, Heikkila HM, Lindstedt KA, Kovanen PT (2007) Improved identification of endothelial erosion by simultaneous detection of endothelial cells (CD31/CD34) and platelets (CD42b). Endothelium 14:81-87

31. Nagata D, Takahashi M, Sawai K, Tagami T, Usui T, Shimatsu A, Hirata Y, Naruse M (2006) Molecular mechanism of the inhibitory effect of aldosterone on endothelial NO synthase activity. Hypertension 48:165-171

32. Oberleithner H (2005) Aldosterone makes human endothelium stiff and vulnerable. Kidney Int 67:1680-1682

33. Oberleithner $\mathrm{H}$ (2007) Is the vascular endothelium under the control of aldosterone? Facts and hypothesis. Pflugers Arch 454:187-193

34. Oberleithner H, Giebisch G, Geibel J (1993) Imaging the lamellipodium of migrating epithelial cells in vivo by atomic force microscopy. Pflugers Arch 425:506-510

35. Oberleithner H, Ludwig T, Riethmuller C, Hillebrand U, Albermann L, Schafer C, Shahin V, Schillers H (2004) Human endothelium: target for aldosterone. Hypertension 43:952-956

36. Oberleithner H, Riethmuller C, Ludwig T, Hausberg M, Schillers H (2006) Aldosterone remodels human endothelium. Acta Physiol (Oxf) 187:305-312

37. Oberleithner H, Riethmuller C, Ludwig T, Shahin V, Stock C, Schwab A, Hausberg M, Kusche K, Schillers H (2006) Differential action of steroid hormones on human endothelium. J Cell Sci 119:1926-1932

38. Oberleithner H, Riethmuller C, Schillers H, MacGregor GA, de Wardener HE, Hausberg M (2007) Plasma sodium stiffens vascular endothelium and reduces nitric oxide release. Proc Natl Acad Sci USA 104:16281-16286

39. Oberleithner H, Schillers H, Wilhelmi M, Butzke D, Danker T (2000) Nuclear pores collapse in response to $\mathrm{CO} 2$ imaged with atomic force microscopy. Pflugers Arch 439:251-255

40. Oberleithner H, Weigt M, Westphale HJ, Wang W (1987) Aldosterone activates $\mathrm{Na}+/ \mathrm{H}+$ exchange and raises cytoplasmic $\mathrm{pH}$ in target cells of the amphibian kidney. Proc Natl Acad Sci USA $84: 1464-1468$

41. Orshal JM, Khalil RA (2004) Gender, sex hormones, and vascular tone. Am J Physiol Regul Integr Comp Physiol 286:R233-R249

42. Peng X, Haldar S, Deshpande S, Irani K, Kass DA (2003) Wall stiffness suppresses Akt/eNOS and cytoprotection in pulseperfused endothelium. Hypertension 41:378-381

43. Pesen D, Hoh JH (2005) Micromechanical architecture of the endothelial cell cortex. Biophys J 88:670-679

44. Pesen D, Hoh JH (2005) Modes of remodeling in the cortical cytoskeleton of vascular endothelial cells. FEBS Lett 579:473-476

45. Pu Q, Neves MF, Virdis A, Touyz RM, Schiffrin EL (2003) Endothelin antagonism on aldosterone-induced oxidative stress and vascular remodeling. Hypertension 42:49-55

46. Quaschning T, Ruschitzka F, Shaw S, Luscher TF (2001) Aldosterone receptor antagonism normalizes vascular function in liquorice-induced hypertension. Hypertension 37:801-805

47. Riethmuller C, Jungmann P, Wegener J, Oberleithner H (2006) Bradykinin shifts endothelial fluid passage from para- to transcellular routes. Pflugers Arch 453:157-165

48. Safar ME, Lacolley P (2007) Disturbance of macro- and microcirculation: relations with pulse pressure and cardiac organ damage. Am J Physiol Heart Circ Physiol 293:H1-H7

49. Schneider SW, Larmer J, Henderson RM, Oberleithner H (1998) Molecular weights of individual proteins correlate with molecular volumes measured by atomic force microscopy. Pflugers Arch 435:362-367

50. Schneider SW, Matzke R, Radmacher M, Oberleithner H (2004) Shape and volume of living aldosterone-sensitive cells imaged with the atomic force microscope. Methods Mol Biol 242:255-279 
51. Schneider SW, Yano Y, Sumpio BE, Jena BP, Geibel JP, Gekle M, Oberleithner H (1997) Rapid aldosterone-induced cell volume increase of endothelial cells measured by the atomic force microscope. Cell Biol Int 21:759-768

52. Schnittler HJ, Schneider SW, Raifer H, Luo F, Dieterich P, Just I, Aktories K (2001) Role of actin filaments in endothelial cell-cell adhesion and membrane stability under fluid shear stress. Pflugers Arch 442:675-687

53. Shahin V (2006) Route of glucocorticoid-induced macromolecules across the nuclear envelope as viewed by atomic force microscopy. Pflugers Arch 453:1-9

54. Simoncini T, Mannella P, Fornari L, Caruso A, Varone G, Genazzani AR (2004) Genomic and non-genomic effects of estrogens on endothelial cells. Steroids 69:537-542

55. Simoncini T, Mannella P, Fornari L, Caruso A, Willis MY, Garibaldi S, Baldacci C, Genazzani AR (2004) Differential signal transduction of progesterone and medroxyprogesterone acetate in human endothelial cells. Endocrinology 145:5745-5756

56. Struthers AD, MacDonald TM (2004) Review of aldosterone- and angiotensin II-induced target organ damage and prevention. Cardiovase Res 61:663-670

57. Suzuki G, Morita H, Mishima T, Sharov VG, Todor A, Tanhehco EJ, Rudolph AE, McMahon EG, Goldstein S, Sabbah HN (2002) Effects of long-term monotherapy with eplerenone, a novel aldosterone blocker, on progression of left ventricular dysfunction and remodeling in dogs with heart failure. Circulation 106:2967-2972

58. Thompson LP, Weiner CP (1997) Long-term estradiol replacement decreases contractility of guinea pig coronary arteries to the thromboxane mimetic U46619. Circulation 95:709-714

59. Wallerath T, Witte K, Schafer SC, Schwarz PM, Prellwitz W, Wohlfart P, Kleinert H, Lehr HA, Lemmer B, Forstermann U
(1999) Down-regulation of the expression of endothelial NO synthase is likely to contribute to glucocorticoid-mediated hypertension. Proc Natl Acad Sci USA 96:13357-13362

60. Wang Q, Chiang ET, Lim M, Lai J, Rogers R, Janmey PA, Shepro D, Doerschuk CM (2001) Changes in the biomechanical properties of neutrophils and endothelial cells during adhesion. Blood 97:660-668

61. Wang Q, Pfeiffer GR, Stevens T, Doerschuk CM (2002) Lung microvascular and arterial endothelial cells differ in their responses to intercellular adhesion molecule-1 ligation. Am J Respir Crit Care Med 166:872-877

62. Wellman GC, Bonev AD, Nelson MT, Brayden JE (1996) Gender differences in coronary artery diameter involve estrogen, nitric oxide, and $\mathrm{Ca}(2+)$-dependent $\mathrm{K}+$ channels. Circ Res 79:10241030

63. Wong S, Brennan FE, Young MJ, Fuller PJ, Cole TJ (2007) A direct effect of aldosterone on endothelin-1 gene expression in vivo. Endocrinology 148:1511-1517

64. Wu L, Xiao B, Jia X, Zhang Y, Lu S, Chen J, Long M (2007) Impact of carrier stiffness and microtopology on two-dimensional kinetics of P-selectin and P-selectin glycoprotein ligand-1 (PSGL-1) interactions. J Biol Chem 282:98469854

65. Wu Y, Zhou Z, Meyerhoff ME (2007) In vitro platelet adhesion on polymeric surfaces with varying fluxes of continuous nitric oxide release. J Biomed Mater Res A 81:956-963

66. Wynne FL, Khalil RA (2003) Testosterone and coronary vascular tone: implications in coronary artery disease. J Endocrinol Invest 26:181-186

67. Yang S, Zhang L (2004) Glucocorticoids and vascular reactivity. Curr Vasc Pharmacol 2:1-12 